\title{
Att vara överens men ändå inte. - Ett bidrag till en fortsatt diskussion om historieskrivning, normativitet och postmodernitet.
}

\author{
Av Roddy Nilsson, doktorand i historia
}

Länk till presentation av Roddy Nilsson

- En välbehövlig debatt

- Den svåra kunskapsteorin

- Nilsson och Strömberg - praktiska postmodernister?

- Ett försök till egen positionering

- Avslutande anmärkningar

\section{En välbehövlig debatt}

Genom regeringens så kallade "reform" av forskarutbildningssystemet har humaniora fått en ordentlig knäpp på näsan och en tydlig uppmaning att rätta in sig i ledet. Den humanistiska forskarutbildningen ska strömlinjeformas och bli mera effektiv, målinriktad och anpassad till samhällets krav. Man måste bli mera inriktad på att producera forskare än forskning. Forskarutbildningens förändring är ytterligare ett steg på den väg mot att göra universitet och högskolor till utbildningsfabriker som anträddes i slutet av 1960-talet. När de gamla fabrikerna tystnar runt om i landet lever taylorismen i den högre utbildningen. Inte minst mot bakgrund av denna oroväckande signal är det glädjande att två doktorander i historia, knutna till Högskolan i Växjö, Jonny Nilsson och Kenneth Strömberg, i föregående nummer av HumaNetten publicerade en provocerande och tankeväckande artikel med titeln Vetenskapens gärdsgårdar och slutna rum - Ett bidrag till en förruttnelseprocess och ett nybygge.[1] I denna diskuterar N/S en rad viktiga frågor som rör framtidens humanistiska forskning. På många punkter är det lätt att dela N/S åsikter, exempelvis i deras plädering för ett mera "phronetiskt" synsätt där eftertanken och omdömet spelar stor roll som en balanserande och kritiserande kraft gentemot en teknisk och rationellt-instrumentell kunskapssyn. På några andra punkter har jag dock en delvis annorlunda uppfattning och det är i första hand dessa jag ska ta upp här.

I sin artikel blandar N/S på ett inte alltid lyckat sätt insiktsfulla iakttagelser och reflexioner kring tillståndet inom humanistisk forskning med kunskapsteoretiska och allmänt historiefilosofiska spekulationer. Förmodligen har detta att göra med det dubbla författarskapet och att man velat ta upp alltför många aspekter till diskussion. På ett par punkter innehåller också N/S artikel oklarheter och direkta självmotsägelser. Här finns bara utrymme för att ta upp några av de frågor som diskuteras i artikeln.[2]

N/S uttrycker syftet med artikeln vara att diskutera hur humanistisk forskning ska kunna nå en högre grad av "meningsfullhet" än vad som är fallet idag. Vidare menar man att det är tid att vitalisera vetenskapen så denna mera kommer i kontakt med människors levnadsvillkor. För att kunna närma sig vardagsnivån bör forskarna tona ner sin teoretiska för-förståelse och istället bli mera ödmjuka och lyhörda inför betydelsen av människors handlingar. I sin kritik mot dagens humanistiska forskning menar N/S vidare att denna till stor del kännetecknas av ett snävt vetenskapsideal och en konsensussyn om vilka teorier och metoder som ska tolereras vilket lett till att man förpassats till rollen av att producera snäll och till samhällsutvecklingen anpassad forskning. Man anser också att detta kan ses 
som en följd av den moderna vetenskapens falska förhoppningar om ett perfekt samhälle och att denna dragit upp gränser mellan tro och vetande som under flera hundra år skadat kreativitet och forskarglädje. Även om det ligger en hel del i denna kritik lider den paradoxalt nog för att vara skriven av historiker av att vara ohistorisk. Med detta menar jag att N/S normativt influerande beskrivning inte beaktat den konkreta historiska situationen och bakgrunden. Om dagens humaniora är snäll och anpassad är detta inte, som N/S hävdar, resultatet av någon långsiktig trend som kan sättas i samband med framväxten av objektivitetsideal och tilltron till säker kunskap. Humaniora som helhet har i vårt land alltid varit "snäll" och anpassad om man med detta menar att den inte sysslat med forskning som ställt sig kritisk vare sig mot statsmakten - oavsett om denna haft allmänt konservativ eller socialdemokratisk karaktär - näringslivet och marknaden eller mot den egna disciplinens utgångspunkter. Det tidiga 1900-talets humaniora, fr a historiedisciplinen, var djupt ideologisk, på samma sätt som den historiskt-kritiska riktningens praktik hade djupgående ideologiska implikationer. De explicita eller implicita ideologiska positionerna avvek inte på något anmärkningsvärt sätt från vad som omfattades av de samhälleliga eliterna. Vid 1970-talets början ifrågasattes denna förmenta objektivitet av framför allt en historiematerialistisk riktning som pläderade för humanioras emancipatoriska potential. Denna riktning förlorade så småningom det mesta av sin kraft i de fall den inte kom att institutionaliseras. Någon tydlig efterträdare har inte vuxit fram även om det på vissa håll har producerats forskning från nyliberala och marknadsfundamentaliska utgångspunkter som ibland gjort anspråk på att vara ett radikalt alternativ.

Ännu mera ohistorisk är N/S syn på följderna av den moderna vetenskapens framväxt. Den process som ledde till uppdelningen och gränsdragningen mellan tro och vetande som N/S ser som en skada för dagens humaniora var inte resultatet av en strid mellan ett objektivistiskt vetenskapsideal och ett annat. Det var en process där en dogmatisk kristendoms monopol på världsförklaringar konfronterades med ett annat - lika dogmatiskt - sätt att se på världen. I denna bemärkelse handlade det därmed mera om att en form av dogmatism ersattes av en annan - inte om att skapa ett kreativt, öppet och pluralistiskt vetenskapsideal.

Den moderna vetenskapen och dess instrumentella rationalitet övertog kyrkans monopol på världsförklaringar. Denna förändringsprocess försiggick under flera hundra år och har för eftervärlden satt avtryck i form av olika strider och uppgörelser, vilka av den segrande vetenskapen setts som en kamp mellan förnuft och vidskepelse. Strider som förknippats med förnuftets oförvitliga hjältar som Galileo, Descartes, Bacon, Voltaire, Darwin och många andra.[3]

I denna process hamnade delvis humaniora utanför, i en position som vi alltsedan dess har behållit. Det är detta "utanförskap" som avspeglas också i våra dagars diskussioner om vad som är humanioras samhälleliga nytta. Humaniora har i moderniteten allt mera tilldelats en terapeutisk funktion som kan läka politikernas, teknikernas och ingenjörernas sargade själar efter det att dessa tagit besvärliga beslut eller producerat tillväxtframbringande nyttigheter när Kjell-Olof Feldt eller Carl Bildt fattat några "nödvändiga" beslut att skära i välfärden kan de på kvällen efter dagens värv sjunka ned i soffan och koppla av med en "god bok". Eller så har den kommit att på marknadens villkor ägna sig åt att framställa en oförarglig och kommersiellt gångbar historia för konsumtion i den växande globala nöjesindustrin. Det är möjligt att det idag finns tecken - t ex det så omtalade ökade intresset för historia på att humanioras position kan förändras. Men jag tror inte vi ska vara säkra på det. Om detta dessutom för historias del fr a ska ske genom produktion av "historia light" i underhållningsversion är det tveksamt om det är något att sträva efter.

\section{Den svåra kunskapsteorin}

N/S riktar i sin artikel ett angrepp mot postmodernismens relativism. Här finns inte utrymme för en längre diskussion kring postmodernismens_4] teoretiska status och implikationer. Jag ska dock ta upp några aspekter på den problematik som N/S artikel föranleder. 
N/S använder i sin artikel begreppet "relativism" på ett sätt som ger upphov till viss förvirring. Man talar om "den postmoderna kunskapsrelativismen" men använder också termerna "relativism" och "kunskapsteoretisk relativism". I det sistnämnda fallet understryker man dessutom att detta inte är detsamma som kunskapsrelativism. På ett ställe används också termen "nihilism" i samband med diskussionen av postmodernismen.

Att hävda en kunskapsrelativistisk ståndpunkt är inte detsamma, vilket N/S tycks hävda, som att förespråka att alla ståndpunkter är lika goda (eller dåliga) utan att hävda att de är relativa i förhållande till ett bestämt sammanhang - socialt, psykiskt, historiskt etc. Att, som N/S också gör, hävda att det postmoderna förnekandet av "sanningen" - om nu detta vore riktigt - också är ett fundament är tämligen poänglöst och saknar hur som helst betydelse utanför det modernistiska tänkande som grundas i just sökandet efter ett sådant fundament. Utanför detta tänkande är nämligen alla positioner relativa.

I diskussionen av relativismen bör man också skilja på en kritik av denna som kunskapsteoretisk ståndpunkt i sig och en kritik av de föregivna eller eventuella implikationer en sådan hållning innebär. Det förstnämnda problemet rör frågan om dess teoretiska hållbarhet, möjligheten av säker kunskap, alternativa ståndpunkter etc. Det andra problemet kan sägas vara en moraliskt-etisk fråga. I detta senare fall skulle jag för klarhetens skull hellre än relativism vilja tala om värdesubjektivism eller värdenihilism som motsatsen till den (värde)objektivism N/S uppenbarligen ansluter sig till. Jag menar därmed att begreppet relativism bör förbehållas den kunskapsteoretiska diskussionen. I diskussionen om kunskapsteoretisk relativism menar jag också att ett lämpligare begrepp är realism snarare än objektivism.

Det sätt att skriva historia som N/S pläderar för förutsätter att man kan skilja mellan fakta och tolkning. Frågan är då med vilka kriterier man kan göra detta? Är ryska revolutionen ett faktum i kunskapsteoretisk mening? Är förintelsen ett faktum i kunskapsteoretisk mening? Är det inte en tolkning? Var går annars gränsen mellan förintelsens objektiva beståndsdelar och dess tolka(n)de? Förintelsens karaktär av katastrof förändrar inte dess teoretiska status utan dess moraliska. Det ska då understrykas att hävdandet att förintelsen inte är ett objektivt faktum i detta sammanhang inte är detsamma som att säga att den (kanske) inte har skett. Förintelsen är en oändlig rad av fakta som först när de ges en kontext (på tolkningsnivån) får status av just förintelse. Det är detta historikern sysslar med oavsett vad han eller hon säger.

Kritiken mot postmodernister för relativism bygger ofta på en missuppfattning. Tvärt emot vad N/S menar förnekar inte postmodernister förekomsten av en oberoende verklighet. I denna mening är också postmodernister realister - till skillnad från filosofiska idealister eller solipsister. Man är också i allmänhet skeptisk till den kunskapsteoretiska realismens mest långtgående anspråk på att våra sinneserfarenheter ger oss direkt tillgång till denna verklighet. Att däremot helt förneka att det finns någon förbindelse mellan verkligheten utanför oss och oss själva torde idag vara högst ovanligt.

N/S menar också i sin kritik av vad man kallar den postmoderna relativismen att det är "i kretsar påverkade av ett sådant tänkande" som förintelsen av judar och andra grupper förnekas. Här menar jag att N/S i sin iver att kritisera postmodernismen tar fel. Vad förnekarna av förintelsen gör är i allmänhet inte att förneka denna händelse eller serie av händelser utifrån postmodernistiska argument eller diskurser utan utifrån strikt modernistiska källkritiska synpunkter. Förnekarna pekar på frånvaron av synliga spår, frånvaron av synliga dokument, omöjligheten av att organisera och hemlighålla en sådan gigantisk operation, att cyklon B-gasen användes till skadedjursbekämpning etc etc. Argumentet bygger dessutom på det minst sagt tveksamma antagandet att postmodernismen eller känslan av att leva i ett postmodernt tillstånd på ett djupgående sätt skulle ha påverkat eller genomsyrat de grupper där dessa tongångar hörs.

En central kritik från postmodernisternas sida mot den moderna vetenskapen har riktat in 
sig på omöjligheten att uppnå sanningen, i bemärkelsen att det finns en förbindelse korrespondens - mellan ett förhållande, tillstånd etc och utsagan om detta. Postmodernister menar i allmänhet att någon sådan förbindelse inte är möjlig då strukturerna i en utsaga (språket eller andra symboler) om något är helt andra än strukturerna eller relationerna $i$ något.

Vad är då "sanning" för postmodernister och vilken funktion har detta begrepp i en postmodernistisk kunskapssyn? Utan att gå in i en alltför lång diskussion kan två påpekanden göras. För det första är "sanning" för postmodernister inte ett kunskapsteoretiskt begrepp i dess moderna betydelse. Det postmoderna sanningsbegreppet kan istället sammanfattas i termer av en diskursrelativ och lingvistiskt konstruerad konvention. Ett påstående eller en utsaga blir eller är "sann" inte för att den korresponderar med förhållanden i verkligheten utan för att någon eller några har makt att definiera något som sant. Förhållandet mellan sanning och makt har tydligast uttryckts av Foucault som en relation där dessa båda företeelser obönhörligen hör samman.[5]

Detta innebär, för det andra, inte heller att postmodernister förnekar att historikern kan få kunskap om enskilda fakta i det förflutna. Man menar dock dels att enskilda fakta i sig är ointressanta eller triviala, dels att de inte är en "sanning". Vad postmodernister ibland kallar sanningsspelet börjar först på tolkningsnivå. Så snart historikern kombinerar två eller flera fakta kommer den tolkande och konstruerande processen in. En historikers arbete handlar aldrig om ett enskilt faktum, utan om den vikt eller betydelse detta får i förhållande till andra fakta. Det handlar om kombinationen av fakta eller om den roll dessa spelar i teorier, förklaringar, perspektiv etc.

Också när N/S ska sammanfatta sin egen ståndpunkt hamnar man i en position där inledningens radikala anslag snabbt krymper ihop och till slut inskränker sig till att endast handla om önskvärdheten av ökad pluralism. N/S hävdar inledningsvis att historien är objektivt verklig och ibland har lämnat spår efter sig. Så långt håller nog alla praktiskt verksamma historiker med. När man ska definiera vad "spår" innebär skriver man att dessa "ibland" är både historien och konstruktioner men något som "vi oftast med källkritiska metoder kan värdera". Definitionen ger upphov till en rad frågor. Vad menar N/S med att spåren ibland är historien? . Vad betyder det att spåren samtidigt är historien och konstruktioner? Om man verkligen menar vad man säger pekar detta kunskapsteoretiskt mot vad som filosofiskt brukar benämnas den "naiva" realismen, dvs föreställningen att verkligheten och representation av denna är identiska. Vad betyder då "ibland"? Att spåren ibland är något annat, alternativt kommer till uttryck på andra sätt? Menar N/S att det är historien eller konstruktionerna eller båda på en gång som vi värderar med källkritiska metoder? Detta blir för mig ändå mera diffust.

Naturligtvis har jag avsiktligt ägnat mig åt en kritisk läsning där jag kanske inte varit helt rättvis mot N/S. En mera "empatisk" läsning av N/S kunskapsteoretiska ståndpunkter hade säkert givit ett annat resultat. Jag vill dock med detta peka på de många och svåra problem en sådan diskussion för med sig. Ändå värre vore dock att - som tyvärr alltför många historiker och andra humanister - aldrig reflektera kring dessa problem.

\section{Nilsson och Strömberg - praktiska postmodernister?}

Den största svagheten med N/S ståndpunkt är emellertid att de menar att sanningen kan avgöras genom källkritiska metoder medan pluralismen kan placeras på tolkningsnivån. Positionen är både teoretiskt och praktiskt ohållbar då det inte finns någon metod källkritisk eller annan - som kan fastslå vad som har hänt eller inte hänt. Detta kan endast ske på tolkningsnivå. Att skilja en diskussion av en händelse i sig från tolkningen av densamma är $\mathrm{m}$ a o inte möjligt. Historikern undersöker inte den förflutna verkligheten i sig utan förflutna tolkningar av denna verklighet. Jag är helt ense med N/S när de argumenterar för att historievetenskapen måste öppna upp för flera förklaringsmöjligheter och teorier men detta måste få konsekvenser på alla nivåer av forskningsprocessen. 
N/S förhållningssätt leder nämligen till en märklig konsekvens. Om N/S, som jag försökt visa, kunskapsteoretiskt intar en både oklar och föga innovativ position förespråkar man däremot i övrigt närmast vad Peter Aronsson kallat en "praktisk postmodernism".[6] Därmed har N/S som började sin vetenskapsteoretiska diskussion med en kritik mot postmodernismen också kommit att slå knut på själva genom att delvis kritisera en teoretisk position som man själv i praktiken pläderar för. N/S menar nämligen att när väl historikerna med källkritiska metoder slagit fast vad som hänt så borde de på tolkningsplanet vara mera generösa och öppna för i princip vilka teorier som helst. Det är sedan upp till forskarsamhället och allmänheten att själva avgöra om de vill sätta tilltro till teorierna. Vad är mera "postmodernt" än att forskaren kan välja vilken teori eller förklaringar han vill och att låta läsarna och andra avgöra om de vill ta till sig den? Vari består skillnaden mellan den relativism N/S anklagar postmodernister för och den öppenhet för i princip vilka teorier som helst som de själva förespråkar? Några sidor längre fram tar man några ytterligare steg mot den postmoderna praktiken genom att peka på vad man kallar de "diskurs-alternativ" som föredömen vilka återfinns hos subkulturer, ursprungsideologiska motståndsfickor, eko-rörelser liksom hos dem som förespråkar en teologiskt grundad världs- och historiesyn eller "flum".[7] N/S betonar också att historien är en reflexion över nuet samtidigt som man på ett sätt som tydligt påminner t ex om Foucaults synsätt framhåller slumpens eller den omedvetna rationalitetens plats i historien.[8]

\section{Ett försök till egen positionering}

Delvis med hjälp av en diskussion som återfinns i sociologen Mats Beronius Genealogi och Sociologi ska jag diskutera några tankar kring hur jag ser på historievetenskapen. [9] Dessa tankar ska inte ses som något färdigt "program" utan som ett avstamp för en fortsatt diskussion.

Beronius representerar ett synsätt som tagit starka intryck från bl a Nietzsche och Foucault.[10] Utgångspunkten är ett anti-realistiskt perspektiv där avvisandet av alla former av korrespondens mellan tänkande och verklighet är centralt. Tänkandet kan inte begrunda verkligheten, menar Beronius, utan bara idéer om verkligheten. Om dessa idéer sedan skulle korrespondera med verkligheten är i praktiken ointressant då vi aldrig kan få detta bekräftat. Det finns dock en faktor som antyder att det är omöjligt att konstruera t ex en vetenskaplig teori som en kopia av verkligheten, framhåller Beronius. Denna faktor återfinns i det sätt som vi tänker våra tankar, nämligen via språket och andra symbolsystem. Eftersom dessa uttrycksformer styrs och struktureras av logiska och grammatiska regler utgör de också begränsningar. Vårt sätt att uttrycka oss blir då med nödvändighet "fiktivt", i betydelsen fingerat och konstruerat. Historikern kan inte beskriva eller tala om verkligheten annat än som ett symboliskt system. Historikerns "berättelse" kan aldrig, liksom inte heller författarens, vara identisk med det den är en berättelse om. Båda sorterar, förenklar och organiserar sitt material och båda arbetar inom en "fiktiv" diskurs. Båda kan t o m sägas vara fiktiva i dubbel bemärkelse. Dels genom att det inte finns någon korrespondens mellan berättelsen och det den berättar om, dels genom att det som t ex Hayden White framhållit - är nödvändigt att konstruera berättelserna för att de ska bli meningsfulla. Det viktiga i Beronius resonemang är, som jag ser det, att vi trots att alla berättelser är fiktioner inte behöver kastas ut i en total relativism eller subjektivism. För även om vetenskapen som text är en fiktion är det ändå meningsfullt att tala om vetenskap som ett sätt att ordna världen som skiljer sig från andra. Vad historikern gör är att han arrangerar fakta till ett begripligt sammanhang, han väljer och organiserar sitt material i enlighet med sitt perspektiv. Detta är det enda sätt vetenskap kan bedrivas på. Utgångspunkten för ett sådant synsätt är filosofiskt sett en pragmatisk tradition där vi utifrån vårt val av perspektiv skapar ett meningsfullt sammanhang. Det är en missuppfattning, understryker Beronius, att tro att vetenskap handlar om att så troget som möjligt återge verkligheten. För även om detta vore möjligt (vilket det naturligtvis inte är) så skulle det i vetenskaplig mening vara meningslöst. Att konstruera en identisk kopia av någonting skulle ju inte ge oss varken djupare förståelse eller ökad kunskap.

Den pragmatiska filosofin betonar att de begrepp och teorier varmed vi beskriver och 
förklarar verkligheten är konventionsstyrda verktyg.[11] Det förflutna består i princip av ett oändligt antal fakta, händelser, rörelser, processer vilka kommer till historikern som text. Från dessa väljer han eller hon sedan utifrån syften, intressen och problemställningar sina infallsvinklar. Alla forskare skriver genom att använda olika språkliga begrepp in sig i en eller flera diskurser. Detta är nödvändigt för att kunna producera en fungerande och därmed kommunikativt möjlig historieskrivning. Enskilda ord eller begrepp får mening enbart i förhållande till varandra, till den diskurs varinom de finns.

En konsekvens av detta blir för historikern att problemformuleringen måste betonas starkare. Det är på denna nivå de teoretiska och normativa ställningstagandena i första hand måste göras. Här gör historikern utifrån sina kunskapsintressen och syften sina val beträffande teorier, metoder, begrepp etc. Det är dessa val som i forskningsprocessen påverkar vad man ser och söker efter, vad som är relevant och viktigt. Hur skiljer annars historikern på viktiga och oviktiga fakta? Varför är det viktigare för historikern att en man (Karl XIV Johan) låg kvar i sängen en stor del av dagen medan en annan (bonden Jon Persson) steg upp och utfordrade sina djur? Är det verkligen viktigare? Eller är det inte så vilket jag vill hävda - att det endast är viktigare utifrån en viss sorts historieskrivning?

Poängen är att historikern inte kan skilja dessa fakta åt bara genom att bedöma eller värdera dem i sin enskildhet. Vad som bedöms vara viktigt avgörs av kunskapsintresse, tolkningsramar, sammanhang, syfte etc. Historikern måste då vara medveten om att det inte finns några neutrala teorier, objektiva begrepp eller någon opartisk undersökningsmetod. Alla verktyg historikern använder är ideologiskt impregnerade.

Historieskrivningen är liksom andra vetenskaper i princip alltid provisorisk - vilket redan den minsta inblick i historiografin visar oss - och föremål för omtolkning. Detta beror inte i första hand - tvärtemot vad som tidigare ofta framhållits bland historiker - på upptäckten av nya källor, utan på anläggandet av nya perspektiv. Om historikern erkänner och drar konsekvenserna av dessa insikter innebär det också att han eller hon på ett mycket mera tydligt sätt än vad som nu vanligen görs måste problematisera sina egna utgångspunkter.

Historikern måste också i sina slutsatser vara medveten om historieskrivningens provisoriska karaktär och därmed bli öppnare och kanske presentera flera tolkningsalternativ inom samma berättelse. Jag menar också att historieskrivningen måste bli mera medvetet historiografisk i sin metod. Skälet till detta är att historikern i mycket högre grad än vad som vanligen erkänns är påverkad av tidigare historieskrivning. Därför måste också historikern integrera historiografin i sitt eget arbete.

Historiker har länge också prioriterat den kritiska granskningen av andra historiker och deras arbeten. Historikern måste emellertid också, i mycket högre grad än idag, inta ett reflexivt och kritiskt förhållningssätt till sig själv och sitt eget arbete. Han eller hon får inte "g(l)ömma" sin position eller roll, sina intressen eller ideologiska preferenser etc. Det går inte längre att tro att man inte intar någon position alls eller att denna enbart är en funktion av rollen som professionell historiker. Det enda möjliga valet är, som den engelske historikern Keith Jenkins framhållit, ett val mellan en historieskrivning som är medveten om vad den håller på med och en som inte är det.[12]

\section{Avslutande anmärkningar}

N/S diskuterar inte alls den "vändning mot språket" (eng "the linguistic turn") som direkt eller indirekt också kommit att påverka historievetenskapen under de senaste åren och vilken lett till, om inte en misstänksamhet mot språket som redskap, så i varje fall en sund vaksamhet gentemot dess faror och begränsningar. Den uppmärksamhet som riktats mot språket har också bidragit till ökad medvetenhet om dess karaktär av arbiträrt och kulturellt format teckensystem. Denna medvetenhet medför bland annat att distinktionen mellan det förflutna som något som skett och historien som skriven text blir mycket skarpare än vad N/S erkänner. Det förflutna kommer alltid till oss som redan tolkad verklighet; vad vi som historiker gör är en tolkning av en tolkning. En annan ytterst viktig fråga som N/S inte 
heller diskuterar är den om framställningsformen.

Det är intressant att N/S inte en enda gång nämner uttrycket "makt" i sin artikel. Är makten frånvarande i deras humanistiska forskarvärld? Befinner sig humanisterna i en maktbefriad sfär - i orkanens öga? Naturligtvis är det inte så och det menar säkert inte N/S heller. Inte desto mindre är det illustrativt att man inte tar upp maktdimensionen i sin diskussion av den humanistiska forskningen. Det visar i varje fall på en prioritering som inte tillmäter denna dimension särskilt stor betydelse. Eller är det tvärtom så att N/S tar denna så pass för given att man därför inte ser den? Jag tror det snarare är så man ska se frånvaron av maktdimensionen i N/S artikel. Dessutom använder N/S en rad andra begrepp som implicerar maktförhållanden. Frågan om makten kan med anledning av N/S artikel emellertid också spetsas till något. Kan man förändra den humanistiska forskningen - i den riktning N/S vill eller någon annan - utan att också förändra de maktrelationer som sätter sin prägel på detta fält?

Humanioras förhållande till vad som med en filosofisk term skulle benämnas "världen" är dels ett vetenskapligt problem av påverkan, inflytande och förhållningssätt. Det handlar om att den instrumentella rationaliteten har trängt in i humanioras värld i form av handtagslösa fönster eller om att den postmoderna vågens förmenta relativism frambringar förintelseförnekare. Men den humanistiska forskningen är också en del av samhället institutionellt sett. Här öppnar sig en stor och svår diskussion som ytterst rör frågor som: Vad ska vi med humaniora till? Vad ska humaniora syssla med? Vem eller vilka ska bestämma vad humaniora ska handla om? N/S menar att humaniora bör ha vad man kallar en "profetisk" uppgift och i högre grad än idag gå emot strömmen, utmana och komma med obekväma frågor. På denna punkt är jag helt överens med N/S.

Jag skulle också vilja gå åtminstone ett halvt steg längre och hävda att humanistisk forskning i dagens samhälle delvis t o m ska stå i opposition till statsmakternas och marknadens krav på anpassning, likriktning och på att producera samhällsrelevant och tillväxtinriktad kunskap. En humanistisk forskning som är enbart "nyttig" och "samhällsrelevant" blir garanterat också en steril och improduktiv forskning. Denna hållning har dock sina risker och placerar ofelbart den humanistiska forskningen i ett prekärt läge inte minst ekonomiskt till anslagsgivande rådsorgan, fonder och andra tänkbara finansiärer. Oavsett vad som sägs om forskningens frihet kommer i praktiken alltid den okonventionella, oprövade och nydanande forskningen att ha det svårare än den anpassade, välkända och redan accepterade när det gäller resurser. Detta är ingenting att moralisera över. Kanske är det så att humaniora måste ta dessa risker för att behålla sin självständighet och självaktning.

Jag tror att N/S som teoretiska realister och praktiska postmodernister är representativa för en ganska stor del av den yngre forskargenerationen i historia i vårt land. Skillnaden består huvudsakligen i att N/S försökt att aktivt reflektera över sin position. Vad jag menar visar sig i N/S artikel avslöjas som teoretiska oklarheter och motsägelser kan förvisso ses som svagheter men är samtidigt ett lovvärt uttryck att börja det tyvärr bland historiker alltför ovanliga arbetet med att reflektera över sina egna och historiedisciplinens teoretiska utgångspunkter och implikationer. Även om jag med min kritik har försökt visa på att N/S utgångspunkter behöver preciseras och utvecklas för att vara teoretiskt hållbara så är detta inte detsamma som de är praktiskt oanvändbara. Jag tror nämligen att de flesta av oss beträffande förhållandet mellan våra teoretiska resonemang och vårt praktiska arbete som historiker uppvisar likartade lakuner och inkonsistenser. Det existerar varken några vetenskapligt-teoretisk konsistenta historiker eller historiska arbeten. Detta är inget speciellt för historiker utan gäller säkerligen lika mycket de flesta andra discipliner. Vetenskapen är en provisorisk verksamhet där också forskaren förändras. Men det är också en följd av människans villkor - historikern är inte och kommer förhoppningsvis aldrig att bli någon dator.

\section{$\underline{\text { Roddy Nilsson }}$}




\section{[1] HumaNetten nr 2 (1998).}

[2] Jag kommer i min artikel helt att uppehålla mig vid historiedisciplinen såsom den traditionellt har definierats. I likhet med Nilsson/Strömberg menar jag dock att vad jag har att säga på det principiella och teoretiska planet även har relevans för det övriga humanistiska fältet och delvis även för vissa andra discipliner.

[3] Se t ex Joyce Appleby/Lynn Hunt/Margaret Jakob, Telling the Truth about History, New York och London 1994, ss kap 1 och 2.

[4] Väl medveten om det problematiska i detta använder jag i Nilssons och Strömbergs efterföljd avsiktligt termen "postmodernism" på ett vagt och tämligen obestämt sätt. Jag har dock mera utförligt diskuterat innebörden i begreppet i annat sammanhang. Se Roddy Nilsson, "Postmodernismen i historieundervisningen - hot eller löfte", i Historielärarnas förenings årsskrift 1996/1997, 1997 s 69-78.

[5] Se t ex Michel Foucault, Power/Knowledge, New York 1981, s 131ff.

[6] Peter Aronsson, "En lomhörd dialog? Den historievetenskapliga debatten på 1990talet", Historisk Tidskrift 1998:1, s 70.

[7] Nilsson/Strömberg: [länk till åsyftat stycke]. Citationstecken i originalet.

[8] Nilsson/Strömberg: [länk till åsyftat stycke].

[9] Mats Beronius, Genealogi och Sociologi. Nietzsche, Foucault och den sociala analysen, Stockholm/Stehag 1991.

[10] Se också Mats Beronius, Bidrag till de sociala undersökningarnas historia eller till den vetenskapliggjorda moralens genealogi, Stockholm/Stehag 1994.

[11] Richard Rorty, Consequences of Pragmatism, Brighton 1982.

[12] Keith Jenkins, Re-thinking History, London 1991, s 69. 